\title{
Gaziantep İlinde Suda Boğulma Vakalarının İncelenmesi
}

\author{
An Examination of Cases of Drowning in Water in Gaziantep Province
}

\begin{abstract}
Adnan TURGUT ${ }^{*}$
Eren AKDAĞ $\breve{T}^{* *}$

$\ddot{O}_{z:}$ Gerek sportif gerekse rekreatif etkinlik bakımından birçok firsatlar sunan su ortamı; insanların doğal yaşam alanı olmamakla beraber fiziksel yapı özellikleri itibariyle su üstünde batmadan durmayı sağlar. Suda boğulma genel tanımlama ile; sıvı bir ortam içerisinde batmadan/dalmadan kaynaklanan solunum bozulması ile giden süreçler dizisidir. Boğulma ciddi bir halk sağlığı problemidir. Kesin rakam belli olamamakla beraber; Türkiye'de her yıl bine yakın insan boğularak can vermektedir. Bu çalışmanın amacı 2005-2016 yılları arasında Gaziantep ilinde suda ölümle sonuçlanan suda boğulma kazalarının incelenmesidir. Bu araştırmada online arama motorlarında 1 Ocak 2005 ile 31 Aralık 2016 tarihleri arasında "suda boğuldu, suya düştü boğuldu, kurtardı boğuldu vb." gibi anahtar kelimeler taranmış ve boğulma ile ilgili haberler günlük olarak toplanmıştır. Kazazedelerin kişisel bilgileri, boğulma yeri, orada bulunma sebebi, su ortamı, günün bölümü vb. gibi veriler kaydedilmiştir. Verilerin analizi SPSS 18.0 kullanılarak yapılmıştır. Sonuç olarak 12 yılda Gaziantep ilinde 97 kişinin suda boğularak hayatını kaybettiği belirlenmiştir. Boğularak ölümlerin önlenebilmesi için küçük yaşlardan itibaren su güvenliği eğitimi verilmeli, su kaynakları etrafında güvenli yüzme alanları oluşturulmalıdır.
\end{abstract}

Anahtar sözcükler: Yüzme, Rekreatif Etkinlik, Suda Boğulma, Su Güvenliği, Gaziantep

\begin{abstract}
Drowning is defined as the process of experiencing respiratory impairment from submersion /immersion in a liquid. Drowning is a serious public health problem. Although the exact number cannot be determined, nearly 1000 people drown every year in Turkey. The aim of this study was to examine cases of accidental death by drowning in water in Gaziantep province between 2005 and 2016. News was searched online via search engines using keywords such as "drowning, drowned by falling in the water, rescuer drowning" etc. in this study. The news was collected day by day for the period between January 1st, 2005 and December 31st, 2016. Personal information concerning the victims, the place of drowning, the reasons for being there, water environment, the time of day, were recorded. Analysis of the data was performed using SPSS 18.0. As a result of this research it was found that 97 people had lost their lives in this 12 year period through drowning in the province of Gaziantep. Water safety training should be provided to children at an early age to prevent deaths by drowning, and safe swimming areas should be built around water resources.
\end{abstract}

Keywords: Swimming, Recreational Activity, Drowning, Water Safety, Gaziantep

\footnotetext{
* Doç. Dr. Akdeniz Üniversitesi, Spor Bilimleri Fakültesi, Beden Eğitimi ve Spor Öğretmenliği Bölümü, Antalya, turgut@akdeniz.edu.tr

*** Akdeniz Üniversitesi Beden Eğitimi ve Spor Bilimleri Yüksek Lisans Programı Öğrencisi, Antalya. erenakdag.ea1@gmail.com
} 


\section{Giriş}

Gerek sportif gerekse rekreatif etkinlik bakımından birçok firsatlar sunan su ortamı; insanların doğal yaşam alanı olmamakla beraber fiziksel yapı özellikleri itibariyle su üstünde batmadan durmayı sağlar. Yelken, sörf, kürek, kano, rafting, scuba, su topu, suda egzersiz, suda fitness gibi sportif etkinliklerin yanında çoğunlukla balık avlamak, serinlemek için suya girmek, piknik yapmak ve benzeri neşelendirici rekreatif faaliyetler esnasında tehlikesiz sayılabilecek su kıyılarından birkaç metre mesafede boğulmalar meydana gelmektedir. Dolayısıyla, yalnız tehlike anında boğulmamak için değil, aynı zamanda da kurtarıcıların hayatını gereksiz yere tehlikeye atmamak için de herkesin yüzmeyi ve suda cankurtarma tekniklerini öğrenmesi gerekmektedir. Günümüzde İngiltere, İsveç, Slovenya gibi birçok gelişmiş ülkede ilköğretim düzeyinde yüzme dersleri ve hatta suda cankurtarma eğitimleri zorunlu hale getirilmiştir. Bu ülkelerde boğulma vakalarındaki oran ülkemize oranla oldukça düşük kalmaktadır (Avrupa'daki Okullarda Beden Eğitimi ve Spor, 2013). Bu nedenle ülkemizde de yüzme sporu eğitimleri ilkokuldan itibaren verilmeli ve zorunlu ders haline getirilmelidir.

Genel tanım olarak suda boğulma; sıvı bir ortam içerisinde batma ve dalmadan kaynaklanan solunum bozulması ile giden süreçler dizisidir (ILS 2007, 7).

Dünya Sağlık Örgütü'ne (WHO) göre; boğulma, kasıtsız olarak yaralanma ile ilişkili ölümlerin 3. en önde gelen sebebidir. Her yıl Dünya'da 372 bin kişi boğularak hayatını kaybetmektedir. Düşük ve orta gelirli ülkelerde boğulma oranları, yüksek gelirli ülkelerden üç kat daha fazladır (Tyler et al. 2017, 1).

Avustralya, Finlandiya ve Amerika Birleşik devletleri gibi ülkelerde boğulma vakalarında ki artış, diğer ülkelere göre daha düşük bulunmuştur. Suda boğularak ölüm, Dünya'da ki her bölgede 1-24 yaşları arasında, en çok görülen on ölüm nedeninden biridir. Boğulan kazazedelerin yarısından fazlası 25 yaş altındadır. Dünya'da her saat 42 insan suda boğularak hayatını kaybetmektedir. Boğulan erkek sayısı yaklaşık olarak kadınların iki katıdır. Boğularak ölüm sayısı, açlıktan ölenlerin 2/3'ü, sıtma hastalığından ölen sayısının yarısından fazladır. Su çevresinde alkol kullanımı, özellikle ergenler ve yetişkinler için pek çok ülkede boğulmak için önemli bir risk faktörünü oluşturmaktadır. İnsanların iş, ulaşım ve tarım için su ile yakın temas halinde bulunduğu düşük ve orta gelirli ülkelerde boğulma oranları oldukça yüksektir (WHO 2014, 3).

Türkiye'nin üç tarafının denizlerle çevrili, nispeten zengin su kaynaklarına sahip olması boğulma oranının fazla olmasında etkilidir. Türkiye'de her yıl ortalama bin kişi suda boğularak yaşamını kaybetmektedir (Benek \& Özcanlı 2015, 187). Gaziantep Akdeniz Bölgesi ile Güneydoğu Anadolu Bölgesi'nin birleştiği noktada konumlanmış bir ilimizdir. Ayrıca bu ilimizin Suriye'ye komşu sınırları bulunmaktadır. Nüfusu yaklaşık iki milyon civarındadır. Göl, gölet, dere, rrmak, nehir, baraj vb. gibi su kaynakları açısından zengindir (Çevre ve Şehircilik Bakanlığı, 2012, 19).

$\mathrm{Bu}$ çalışmada, Gaziantep ilinde suda boğulma sonucunda meydana gelen ölümlerin yillara göre sayıları, kurbanların demografik özellikleri, boğulmanın gerçekleştiği su ortamı ve yeri, kurbanların niçin orada bulunduklarının incelenmesi amaçlanmıştır.

\section{Yöntem}

$\mathrm{Bu}$ çalışmada Gaziantep ilinde meydana gelen suda boğulma vakalarını araştırmak için online arama motorlarından "suda boğuldu, suya düştü boğuldu, kurtardı boğuldu, yüzerken boğuldu $v b$." gibi anahtar kelimeler kullanılarak suda boğulma ile ilgili haberler 1 Ocak 2005 ile 31 Aralık 2016 tarihleri arasında günlük olarak toplanmıştır. Kazazedelerin kişisel bilgileri, boğulma yeri, niçin orada bulundukları, su ortamı vb. gibi veriler kaydedilmiştir. Verilerin analizi SPSS 18.0 paket programı kullanılarak değerlendirilmiştir. 


\section{Bulgular}

Tablo 1. Kazazedelerin Yaşlara Göre Dağılımı

\begin{tabular}{ccc}
\hline & f & $\%$ \\
\hline $1-9$ & 14 & 14,4 \\
$10-19$ & 44 & 45,5 \\
$20-29$ & 18 & 18,5 \\
$30-39$ & 5 & 5,2 \\
$40-49$ & 7 & 7,2 \\
$50-59$ & 7 & 7,2 \\
$60+$ & 1 & 1 \\
Bilinmiyor & 1 & 1 \\
\hline Toplam & 97 & 100,0 \\
\hline
\end{tabular}

Tablo 1: Gaziantep ilinde 20052016 y1lları arasinda 97 (ortalama yaş=21,4 yıl, yaş aralığı: 1-63 yıl) kişi suda boğulma sonucu hayatını kaybetmiştir.

Tablo 2. Kazazedelerin Yillara ve Cinsiyet Göre Dağlımı

\begin{tabular}{|c|c|c|c|c|c|c|c|}
\hline & Erkek & $\%$ & Kadın & $\%$ & Toplam & $\%$ & Tablo 2: Kazazedelerin \\
\hline 2005 & 0 & 0 & 0 & 0 & 0 & 0 & 16’s1 kadın $(\% 16,5)$ \\
\hline 2006 & 2 & 2,1 & 1 & 1,0 & 3 & 3,1 & 81'i $(\% 83,5)$ erkektir. \\
\hline 2007 & 5 & 2,1 & 1 & 1,0 & 3 & 5,2 & Y1llara göre boğulma \\
\hline 2008 & 8 & 8,2 & 1 & 1,0 & 9 & 9,3 & say1s1: \\
\hline 2009 & 16 & 16,4 & 2 & 2,1 & 18 & 18,5 & 2009'da $18(\% 18,6)$, \\
\hline 2010 & 8 & 8,2 & 1 & 1,0 & 9 & 9,3 & 2011 'de $15(\% 15,5)$, \\
\hline 2011 & 15 & 15,5 & 0 & 0 & 15 & 15,5 & 2014'de $11(\% 11,3)$, \\
\hline 2012 & 1 & 1,0 & 7 & 7,2 & 8 & 8,2 & 2010 'da 9'dur $(\% 9,3)$. \\
\hline 2013 & 6 & 6,2 & 2 & 2,1 & 8 & 8,2 & \\
\hline 2014 & 10 & 10,3 & 1 & 1,0 & 11 & 11,3 & \\
\hline 2015 & 6 & 6,2 & 0 & 0 & 6 & 6,2 & \\
\hline 2016 & 4 & 4,1 & 1 & 1,0 & 5 & 5,1 & \\
\hline Toplam & 81 & 83,6 & 16 & 16,4 & 97 & 100 & \\
\hline
\end{tabular}

Tablo 3. Kazazedelerin Aylara Göre Dağllımı

\begin{tabular}{ccc}
\hline & f & $\%$ \\
\hline Şubat & 2 & 2,1 \\
Mart & 5 & 5,2 \\
Nisan & 4 & 4,1 \\
Mayis & 14 & 14,4 \\
Haziran & 24 & 24,7 \\
Temmuz & 16 & 16,5 \\
Ağustos & 15 & 15,5 \\
Eylül & 6 & 6,2 \\
Ekim & 7 & 7,2 \\
Kasım & 3 & 3,1 \\
Aralik & 1 & 1,0 \\
\hline Toplam & 97 & 100,0
\end{tabular}

Tablo 3: Aylara göre

boğulma sayıları;

Haziran $24(\% 24,7)$,

Temmuz $16(\% 16,5)$,

Ağustos $15(\% 15,5)$,

Mayıs 14'tür $(\% 14,4)$. 
Tablo 4. Kazazedelerin İlçelere Göre Dağlımı

\begin{tabular}{ccc}
\hline & f & $\%$ \\
\hline Araban & 9 & 9,3 \\
Islahiye & 15 & 15,5 \\
Karkamış & 10 & 10,3 \\
Merkez & 9 & 9,3 \\
Nizip & 12 & 12,4 \\
Nurdağı & 2 & 2,1 \\
Oğuzeli & 11 & 11,3 \\
Şahinbey & 5 & 5,2 \\
Şehitkamil & 7 & 7,2 \\
Yavuzeli & 5 & 5,2 \\
Yeri belirtilmemiş & 12 & 12,4 \\
\hline Toplam & 97 & 100,0 \\
\hline
\end{tabular}

Tablo 5. Kazazedelerin Olay Yerinde Bulunma Sebepleri

\begin{tabular}{lcc}
\hline & f & \% \\
\hline Serinlemek & 31 & 32,0 \\
Piknik yapmak & 15 & 15,5 \\
Balik avlamak & 10 & 10,3 \\
Bir araç ile seyahat & 4 & 4,1 \\
Oyun oynamak & 11 & 11,3 \\
Ikamet etmek & 4 & 4,1 \\
Gezinti & 13 & 13,4 \\
Intihar & 1 & 1,0 \\
IŞ & 8 & 8,2 \\
\hline Toplam & 97 & 100,0 \\
\hline
\end{tabular}

Tablo 6. Suda Boğulmaların Gerçekleşme Şekilleri

\begin{tabular}{lcc}
\hline & $\mathbf{f}$ & $\mathbf{\%}$ \\
\hline Yüzerken & 39 & 40,2 \\
Intihar & 1 & 1,0 \\
Trafik kazas1 & 1 & 1,0 \\
Suya düşme & 29 & 29,9 \\
Suya atılma & 1 & 1,0 \\
Bot-tekneden düşerek & 4 & 4,1 \\
Herhangi birşeyi kurtarırken & 15 & 15,5 \\
Sele kapilma & 6 & 6,2 \\
Elektrik çarpmas1 & 1 & 1,0 \\
\hline Toplam & 97 & 100,0 \\
\hline
\end{tabular}

Tablo 4: İlçelere göre boğulma sayıları; Islahiye $14(\% 14,4)$, Nizip $12(\% 12,4)$, Oğuzeli $11(\% 11,3)$, Karkamış 9'dur $(\% 9,3)$. 
Tablo 7. Vakalara Göre Boğulma Sayıları

\begin{tabular}{ccc}
\hline Aynı Vakada Boğulan Sayıs1 & f & \% \\
\hline 1 & 67 & 69,1 \\
2 & 24 & 24,7 \\
3 & 6 & 6,2 \\
\hline Toplam & 97 & 100,0
\end{tabular}

Tablo 8. Kazazedelerin Uyruğu

\begin{tabular}{ccc}
\hline & f & $\mathbf{\%}$ \\
\hline Türk & 91 & 93,8 \\
Suriyeli & 6 & 6,2 \\
\hline Toplam & 97 & 100,0 \\
\hline
\end{tabular}

Tablo 9. Boğulmanın Gerçekleştiği Su Ortamı

\begin{tabular}{lcc}
\hline & f & $\%$ \\
\hline Dere-Irmak-Nehir & 35 & 36,1 \\
Göl/gölet & 23 & 23,7 \\
Havuz & 6 & 6,2 \\
Foseptik & 2 & 2,1 \\
Sel & 6 & 6,2 \\
Sulama kanalı & 6 & 6,2 \\
Baraj & 11 & 11,3 \\
Kuyu & 2 & 2,1 \\
Leğen-Kova-Kazan & 3 & 3,1 \\
Hayvan sulama çukuru & 1 & 1,0 \\
Çukur & 2 & 2,1 \\
\hline Toplam & 97 & 100,0 \\
\hline
\end{tabular}

Tablo 10. Boğulmanın Gerçekleştiği Dere/Irmak/Nehir

\begin{tabular}{lcc}
\hline & f & \% \\
\hline Deliçay deresi & 1 & 1,0 \\
Frrat nehri & 22 & 22,7 \\
Karasu çayı & 2 & 2,1 \\
Sitmapınar çay1 & 3 & 3,1 \\
Ismi belirtilmeyen Dere/Irmak/Nehir & 7 & 7,2 \\
Diğer su kaynakları & 62 & 63,9 \\
\hline Toplam & 97 & 100,0 \\
\hline
\end{tabular}

Tablo 7: Kazazedelerin 1'i zihinsel engelli 1'ininde sara hastası olduğu belirlenmiştir. 12 vakada aynı anda 2 kişi, 2 vakada aynı anda 3 kişi boğularak hayatını kaybetmiştir.

Tablo 8: Kazazedelerin 6's1 $(\% 6,2)$ yabanc1 uyruklu olup Suriyelidir.

Tablo 9: Boğulmaların gerçekleştiği su ortamı; $36(\% 37,1)$ dere/1rmak/ nehir, $21(\% 21,6)$ göl/gölet, $11(\% 11,3)$ baraj, 6's1 $(\% 6,2)$ sulama kanalıdır.

Tablo 10: Su kaynaklarına göre boğulmalar; $22(\% 22,7)$ Firat nehri, $6(\% 6,2)$ Alleben göleti, $5(\% 5,2)$ Kayacık baraj1, $3(\% 3,1)$ Tahtaköprü baraj1, $3(\% 3,1)$ Sitmapınar çayıdır. 
Tablo 11. Boğulmanın Gerçekleştiği Gö1/gölet

\begin{tabular}{lcc}
\hline & f & $\%$ \\
\hline Ac1su göleti & 1 & 1,0 \\
Alıcı göleti & 1 & 1,0 \\
Alleben göleti & 6 & 6,2 \\
Burç göleti & 1 & 1,0 \\
Jandarma gölü & 1 & 1,0 \\
Ismi belirtilmeyen & 13 & 13,5 \\
göl/gölet & & 76,3 \\
Diğer su kaynakları & 74 & 100,0 \\
\hline Toplam & 97 &
\end{tabular}

Tablo 12. Boğulmanm Gerçekleştiği Barajlar

\begin{tabular}{lcc}
\hline & f & $\%$ \\
\hline Birecik & 1 & 1,0 \\
Karkamış & 2 & 2,1 \\
Kayacık & 5 & 5,2 \\
Tahta köprü & 3 & 3,1 \\
Diğer su kaynakları & 86 & 88,6 \\
\hline Toplam & 97 & 100,0 \\
\hline
\end{tabular}

Tablo 13. Boğulmanın Geçekleştiği Havuz Türleri

\begin{tabular}{lcc}
\hline & f & $\%$ \\
\hline Sulama havuzu & 2 & 2,1 \\
Otel havuzu & 2 & 2,1 \\
Aquapark havuzu & 2 & 2,1 \\
Diğer su kaynakları & 91 & 93,7 \\
\hline Toplam & 97 & 100,0 \\
\hline
\end{tabular}

Tablo 11: Boğulmanın Gerçekleştiği Göl/Gölet sayı ve oranları.
Tablo 12: Boğulmanın Gerçekleştiği Barajlar sayı ve oranları.

\section{Tartışma}

Yapılan bu çalışma ile Gaziantep ilinde 12 yıl içerisinde 97 kişinin suda boğularak hayatını kaybettiği belirlenmiştir. Adana'da 1997-2006 yılları arasında yapılan çalışmada 511 kişi (Arslan et al. 2008, 14), Şanlıurfa'da 2001-2008 yılları arasında yapılan çalışmada 189 kişi (Benek \& Özcanlı 2015, 193), Eskişehir'de 2001-2010 yılları arasında yapılan çalışmada 83 kişi (Karbeyaz et al. 2012, 12), Elazığ'da 2005-2012 yılları arasında yapılan çalışmada 100 kişi (Türkoğlu et al. 2014, 146), Diyarbakır'da 1996-1998 yılları arasında yapılan çalışmada 46 kişi suda boğularak hayatını kaybetmiştir (Tıraşçı \& Gören 2000, 140).

Ülkemizde suda boğulma vakaları ile ilgili yapılan birkaç çalışmada yaş grupları aralığı şöyledir. Eskişehir'de yapılan çalışmada kazazedelerin yaşlarının en çok 10-19 yaş aralığında (\%31,3) (Karbeyaz et al. 2012, 12), Şanlıurfa'da yapılan çalışmada 0-5 yaş aralı̆̆ında $(\% 37,6)$ (Benek \& Özcanlı 2015, 198) olduğu tespit edilmiştir. Yapılan bu çalışmada ise kazazedeler 1019 yaş $(\% 45,5)$ aralığındadır. Yapılan çalışmalar incelendiğinde ülkemizde suda boğulma en çok 20 yaşın altındaki kişilerde görülmektedir.

Yapılan bu çalışmada kazazedeler cinsiyetleri açısından incelendiğinde 16'sının (\%16,5) 
kadın, 81'inin $(\% 83,5)$ erkek olduğu tespit edilmiştir. Karbeyaz et al. $(2012,14)$ 'nın çalışmasında kazazedelerin \%22,9'u kadın, \%77,1'i erkek, Benek ve Özcanlı $(2015,196)$ 'nın çalışmasında \%24,3'ü kadın, \%75,7'si erkek, Arslan et al. (2008, 14)'nın çalışmasında \%15,8'i kadın, \%84,1'i erkek, Türkoğlu et al. $(2014,146)$ 'nın çalışmasında \%32'si kadın, \%68'i erkek olduğu tespit edilmiştir. Avustralya'da 2016 yılında suda boğulanların \%17'si kadın, \%83'ü erkektir (Royal Life Saving Society Australia 2016, 2). Bu çalışmalar değerlendirildiğinde erkeklerin suda boğulma oranının kadınlardan daha fazla olduğu görülmektedir. Bunun nedeninin erkeklerin kadınlara göre daha fazla su ortamında bulunmasına bağlanmaktadır.

Yapılan çalışmalarda suda boğulmaların en çok yaz aylarında gerçekleştiği görülmektedir. Kanada'da yapılan benzer bir çalışmada en çok suda boğulma \%18 ile Temmuz ayında tespit edilmiştir (Canadian Drowning Report 2016, 4). Karbeyaz et al. (2012, 12)'nın çalışmasında Türkiye'de en çok suda boğulmanın \%22 ile Ağustos ayında, bu çalışmada ise Gaziantep ilinde en çok suda boğulmanın \%24,7 ile Haziran ayında gerçekleştiği belirlenmiştir. Bunu sebebinin yaz aylarında sıcaktan bunalan insanların serinlemek amacıyla su kaynaklarına yönelmesinden kaynaklandığı düşünülmektedir.

$\mathrm{Bu}$ çalışmada ilçelere göre boğulma sayıları; Islahiye $14(\% 14,4)$, Nizip $12(\% 12,4)$, Oğuzeli $11(\% 11,3)$, Karkamış $9(\% 9,3)$ olarak belirlenmiştir. Fırat Nehri, Nizip ve Karkamış ilçelerinden geçmektedir. Bu durum bu ilçelerde serinlemek amaciyla Firat Nehri'ne giren kişilerde boğulma vakalarının fazla olmasına neden olmaktadır.

Avustralya'da (RLSSA 2016, 7) ve Kanada'da (Canadian Drowning Report, 2016) yapilan çalışmalarda boğulmanın en çok yüzme esnasında gerçekleştiği belirlenmiştir. Bu çalışmada kazazedeler sırasıyla en çok yüzme ve serinleme esnasında boğulmuştur (39 kişi; \%40,2). Daha sonraki boğulma nedenleri sırasıyla suya düşerek (29 kişi; \%29,9), herhangi bir şeyi kurtarırken (15 kişi; \%15,5), sele kapılarak (6 kişi; \%6,2) meydana geldiği ortaya çıkmıştır. Balıkçıların suya girerek ağ sermesi, düşen oltayı almaya çalışması, su içinde balık avlamaya çalışması balık avlayan birçok kişinin boğulmasına sebep olmuştur. İnsanların yüzme bilmemesine rağmen derin sulara girmesi, su ortamında tek başına olması, bir kişiyi ya da cismi kurtarmaya çalışması birçok kişinin canına mal olmuştur. Turgut ve Turgut $(2012,65) 2005-2008$ yılları arasında Türkiye'de yaptıkları çalışmada 114 kişinin, bir kişiyi ya da cismi kurtarmaya çalışırken boğulduğunu belirtmiştir. Kazazedeyi kurtarmaya çalışan kurtarıcının boğulma oranının yüksek olması ilginç bir durumdur. Can kurtarma eğitimlerinde en önemli şey kurtarıcının kendi güvenliğini sağlamasıdır. Kurtarıcı kazazedeye ilk müdahaleyi kontaksız bir şekilde, bir materyal ile yapmalı, materyal yoksa kendi güvenliğini sağlayarak müdahale etmelidir. Bu sonuç bize ülkemizde can kurtarma eğitiminin eksik dolayısıyla da bu eğitimin ne kadar gerekli ve önemli olduğunu göstermektedir.

Boğulmanın en çok olduğu su ortamı Arslan et al. (2008)'nın çalışmasına göre sulama kanalı $(\% 61,4)$ iken, Türkoğlu et al. $(2014,16)$ 'nın çalışmasında baraj $(\% 44,4)$, Benek ve Özcanlı $(2015,197)$ 'nın çalışmasında sulama kanalı $(\% 67,7)$, Karbeyaz et al. $(2012,12)$ 'nın çalışmasında dere/1rmak/nehir (\%64,4), Kanada'da yapılan çalışmada göl/gölet (\%37) (Canadian Drowning Report 2016, 5), bu çalışmada ise dere/1rmak/nehir (\%37,1) olarak ortaya çıkmıştır. Boğulmanın gerçekleştiği su ortamının farklılık göstermesi her araştırmanın yapıldığı coğrafi konumdaki su kaynaklarının çeşitliliğine göre değişkenlik göstermektedir.

$\mathrm{Bu}$ araştırmada en çok suda boğulmanın gerçekleştiği su kaynakları sırasıyla; Fırat nehri $(\% 22,7)$, Alleben göleti $(\% 5,2)$, Kayacık barajı $(\% 3,1)$, Tahtaköprü $(\% 3,1)$ barajıdır. Frrat Nehri debisi yüksek bir su kaynağıdır. Bu nehre serinlemek ve yüzmek amacıyla giren kişilerin muhtemelen akıntıya kapılması ve paniklemesi boğulma vakalarını artırmıştır. 
Verilerimize göre 67 vakada birer kişi suda boğulurken, 12 vakada 2'şer kişi, 2 vakada da 3'er kişi boğulmuştur. Boğulan kişiyi kurtarmak isteyen yakınları ya da çevredeki kişilerinde boğulması aynı vakadaki ölüm sayısını artırmıştır.

\section{Sonuç}

2005-2016 yılları arasında Gaziantep ilinde 97 kişi suda boğularak hayatını kaybetmiştir. Boğulan kişiler daha önce de açıklandığı üzere genç ve yetişkin kişilerdir. Bu da bize yüzme sporunun çok küçük yaşlardan itibaren verilmesi gerekliliğini göstermektedir. Suda boğulmayı önlemek için küçük yaşlardan itibaren su güvenliği, suda can kurtarma ve ilk yardım eğitimlerinin de verilmesi gerektiğini göstermektedir. Yaz aylarında okulların tatil olması, serinlemek için daha çok su kaynaklarının kullanımı, balık tutma ve piknik yapma gibi etkinliklerin bu mevsimde daha çok tercih edilmesi suda boğulma tehlikesini artırmaktadır. Özellikle yaz öncesi su güvenliği hakkında insanlar bilinçlendirilmeli, kamu spotu reklamları yapılmalıdır. Su kaynakları kenarına bilgi ve uyarı tabelaları asılarak insanlar su kaynağı hakkında bilinçlendirilmeli, güvenli yüzme alanları oluşturulmalıdır. İnsanların yoğun suya girdiği yerlerde can kurtaran ve kurtarma ekipmanlarının bulunmasını zorunlu hale getirilmelidir.

\section{KAYNAKÇA}

Arslan M. M., Çekin N., Hilal A. \& Kar H. (2008). “Adana'da 1997-2006 Yilları Arasında Meydana Gelen Suda Boğulma Olgularının İncelenmesi”. Türkiye Klinikler J Foren Med. 5 (2008) 13-18.

Benek S. \& Özcanlı M. (2015). "Şanlıurfa İlinde Boğulma Vakalarının İncelenmesi (2001-2008)". Marmara Coğrafya Dergisi (2015) 184-203.

ILS (2007). World Drowning Report 2007 Edition. Kaynak: https://www.ilsf.org/sites/ilsf.org/files/ filefield/world-drowning-report-final-sept-27-2007.pdf . indirilme tarihi: 02.11.2017

Karbeyaz K., Melez İ. E., Melez O. D., Akkaya H. \& Özsoy S. (2012). "Eskişehir İlinde Suda Ölü Bulunma Olgularında Çevresel Değerlendirme ve Adli Yaklaşım”. Adli Tip Dergisi 1 (2012) 6-19.

Tyler M., Richards D., Nielsen C., Saghafi O., Morse E., Carey R. \& Jacquet G. (2017). "The Epidemiology of Drowning in Low- and Middle-Income Countries: A Systematic Review". BMC Public Health 17/1 (2017) 413.

Tıraşçı Y. \& Gören S. (2000). "Diyarbakır'da Suda Boğulma Olgularının Değerlendirilmesi”. Dicle Tip Dergisi 27 (2000) 139-144.

Turgut A. \& Turgut T. (2012). "A Study on Rescuer Drowning and Multiple Drowning Incidents". Journal of Safety Research 43 (2012) 129-132.

Türkoğlu A., Tokdemir M., Börk T., Tunçez T., Yaprak B. \& Şen M. (2014). "Elazığ'da 2005-2012 Yılları Arasında Meydana Gelen Suda Boğulma Olgularının Retrospektif Değerlendirilmesi”. Fırat Tip Dergisi 19/3 (2014) 145-150.

\section{Elektronik Kaynaklar}

2012 Yılı Gaziantep İl Çevre Durum Raporu www.csb.gov.tr/db/ced/editordosya/Gaziantep_icdr2012(1).pdf

Avrupa'daki Okullarda Beden Eğitimi ve Spor http://eacea.ec.europa.eu/education/eurydice/documents/ thematic_reports/150TR.pdf

Canadian Drowning Report (2016). Kaynak: http://www.lifesavingsociety.com/media/241812/canadiandrowningreport_english_web.pdf . Erişim Tarihi: 02.11.2017

Royal Life Saving National Drowning Report. (2016). Kaynak: https://www.royallifesaving.com.au/ _data/assets/pdf_file/0004/18085/RLS_NDR2016_ReportLR.pdf .

World Health Organization. (2014) World Drowning Report 2014 Edition. Kaynak: http://www.who.int/ violence_injury_prevention/global_report_drowning/Final_report_full_web.pdf 